\title{
The Comparison and Inspiration of Outcome-based Curriculum Design in Canada and Higher Vocational Education in China
}

\author{
Jingxia Wang \\ School of electronic and communication engineering, Shenzhen Polytechnic, Shenzhen 518055, \\ PRC \\ wjx2000@szpt.edu.cn
}

Keywords: Outcome-based; learning outcomes; curriculum system; job post

\begin{abstract}
This paper describes the basic ideas of the Canadian outcome-based education (OBE) mode. Real-world-relevant and measurable learning outcomes are the cores of OBE. A prescribed syntactical pattern is given to describe learning outcome. Then, the development procedures for curriculum system under the OBE pattern are put forward. Compare with the Chinese curriculum system design process based on job post, this paper summarizes the inspirations to higher vocational education in China.
\end{abstract}

\section{Introduction}

Outcome-based is an education reform pattern, its ideas come from the United States the last century. In the $1950 \mathrm{~s}$, American educators noted that the concept of the teaching goal. To the 1990s, this education mode has been got an impact in the education system gradually. After years of repeated practice tests, OBE model has been developing rapidly in the 21st century [1]. In recent years, the Hong Kong education funding council gradually carried out this teaching idea in institutions of higher learning reform. Hong Kong polytechnic university as early as the beginning of 2004 have begun to incorporate the outcomes-based teaching idea in the school curriculum, and made significant achievements in the teaching and assessment [2]. This paper studies the specialty curriculum system design approaches of Canadian OBE model, which is compared with curriculum design methods of career-oriented in China. The inspiration is given for Chinese higher vocational education.

\section{OBE Model Overview}

The fundamental ideas of OBE model come from John Piaget. "The principal goal of education is to create 'people' who are capable of doing new things, not simply of repeating what other generations have done, 'people' who are creative, inventive and discoverers.” It can simply be summarized by the following three sentences: learning that should last for the rest of life; practical, useable teaching and learning; integration of learning activities that enhance developing critical thinking skills and learning resilience [3]. It includes the following two key points: First, clearly define the real-world-relevant and measurable learning outcomes, and then all educational activities are built to achieve the learning outcomes. Learning outcome is a very broad concept. It is what the learner will be able to do: an observable, measurable performance or actions, including all kinds of knowledge, skill, ability, quality, etc., at the end of a series of learning activities. Therefore, OBE is also known as "career-based education" [4].

\section{Description of Learning Outcomes}

How to construct learning outcomes, which are real-world-relevant and measurable, is the key of OBE model. Learning outcomes must be clear and measurable [3]. The descriptions of learning outcomes include the following four parts. The first is the stem. The sentence "Students will be able to" will be used to determine what the students will be able to do after they complete the learning 
activities. For example, the following sentence can be used to describe the stem part, "Upon successfully completion of this course, the students will be able to". The second part is one or two verbs in infinitive tense. Measurable verb must be used to describe, that is, the action can be objectively tested, e.g. use, name etc. The following verbs that we often use, "understand", "master" and "know", can't accurately describe the learning outcomes because they are not measurable and testable. The third part is a noun phrase, which defines the activities that the verb describes. "Upon successfully completion of this course, the students will be able to compose business documents" is an example for learning outcome description. The fourth part is a prepositional phrase which is optional. It describes the key details about the skills, e.g. "Upon successfully completion of this course, the students will be able to compose business documents that demonstrate critical thinking skills, command of standard grammar, and logical organization”.

Therefore, learning outcome statements typically follow an institutionally prescribed syntactical pattern: a phrase describing the learning participant + an infinitive verb that describes what the learning participant will be able to do + a phrase that describes the conditions under which the participant will complete the task.

Learning outcomes can not be described by the teachers according to the teaching content and teaching hours, or other conditions. It is a contract between the workplace, the community, the institution, its teachers, and its students [3,5].

\section{OBE Curriculum Design in Canada}

Curriculum design based on OBE includes the following four steps: program learning outcomes descriptions, related secondary descriptions, courses development and program map development. As a simple example, how to develop the program curriculum map for the childcare program will be described to illustrate the above four steps.

Program Learning Outcomes Descriptions. The actions that the children's nursing students should be able to do after graduation can be divided into the following three aspects: body care (including feeding, bathing, and ensuring safety, playing, etc.), mental training (including literacy, singing, dancing, painting, reading, etc.) and emotional development (including sharing, participation, cooperation, etc.).

Related Secondary Descriptions. Describe above three types of learning outcomes related matters, including of basic concepts, issues and skills. For example, the related basic concepts about body care: children's body structure, children's habits and customs, etc; related issues: get sick, choke while feeding, etc; related skills: feeding, bathing, and so on.

Courses Development. First, summarize related descriptions about three learning outcomes, the following three courses should be set: safety, child psychology and child care skills. Then, the course learning outcomes are designed for every course. Each learning outcome includes related professional learning outcomes description, related summative evaluation, course content, teaching activities, formative assessment strategy and teaching resources, etc.

Program Map Development. According to the course content, courses are arranged into different semesters and the program curriculum map is got. The student elective admission requirements of the professional, namely entry requirements, are listed at first. Then give each semester courses and credits, including public courses, compulsory courses and elective courses as well as courses relationship between the leading and trailing. Finally describe the program learning outcomes. The abridged general view of the program map based OBE is shown in Fig. 1.

\section{Career-oriented Curriculum Design in China}

In recent years, professional colleges across the country in China have been vigorously exploring the training of qualified senior technicians who meet the market demands. The idea of this career-oriented curriculum design method comes from the educational objectives of higher vocational education. Higher vocational education is the education of knowledge, skills and attitudes 
to adapt to the needs of some kind of professional post group or business areas. Therefore, vocational education must have a clear purpose, for a specific career positions design. It is the important guarantee of realizing this task to set up the cultivation mode taking job post as the core. Career-oriented curriculum design includes the following four steps: find suitable job post in the profession; describe the job post; determine cultivation objectives of the major; build curriculums map [6].

Find Suitable Job Post in the Profession. Do a series of research work and find suitable job post in the profession is the first step of curriculum system development. Research the national policy, industrial planning and regional economic to know the industrial structure, and understand the industry background, and build relationship with relevant enterprise. Get the post configuration, personnel structure, personnel needs and job posts by visiting industry associations and companies.

Describe the Job Post. Based on school-enterprise cooperation mechanisms, the job posts are analyzed to get a detailed description of each post's ability and quality requirements, and then sum up the cultivation objectives of the major.

Determine Cultivation Objectives of the Major. Starting from the job post descriptions, analyze and summarize the professional quality and ability of all job posts, draw students should have the ability, including the basic ability (professional quality), basic professional skills and expertise. These are the content of the training objectives of the major. Training objectives are the basis for curriculum system construction and lead the direction of major development.

Build Curriculum Map of the Program. Based on the training goal, corresponding to the basic ability, basic professional skills and expertise, build a pyramid-shaped course system structure. Located at the base of the pyramid, there is the platform for the cultural quality courses, to cultivate the students' basic ability and basic quality which is every job post needs. Then the professional foundation courses train students the basic professional ability and professional quality, and make students achieve sustainable development. Followed by the professional courses to cultivate students expertise in the professional field. At the top of pyramid, there are the courses about job post, realizing zero distance between learning and employment. A pyramid-shaped courses system is shown in Fig. 2.

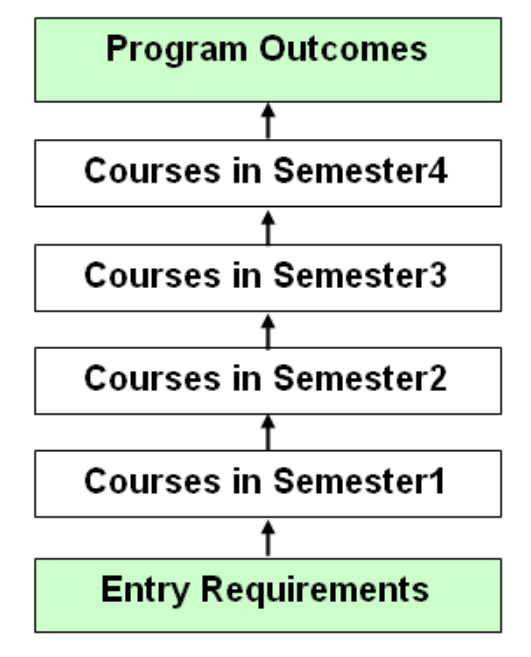

Fig. 1 The abridged general view of the program map based OBE

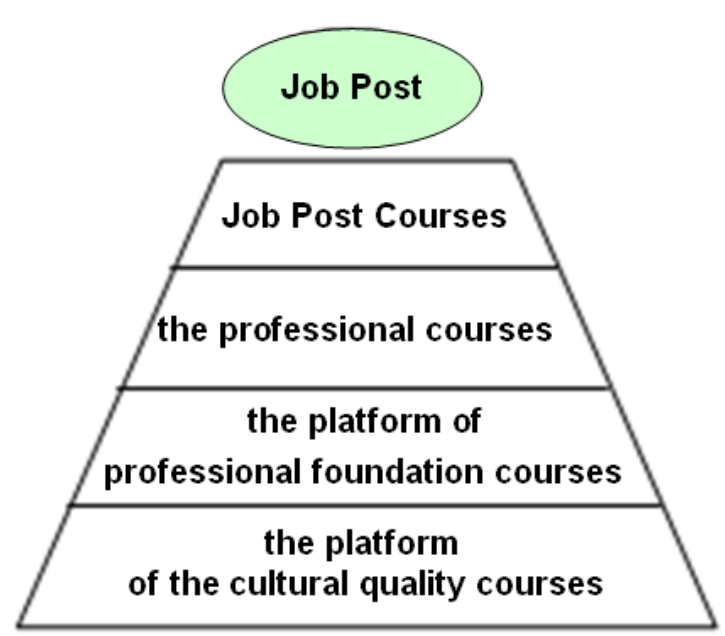

Fig. 2 A pyramid-shaped courses system

\section{Comparison and Inspiration}


Both outcome-based curriculum design method in Canada and the career-oriented curriculum design method in China are proven, mature curriculum development methodology. There are similarities between them as following. (1) Starting point: based on the industries and enterprises; (2) Participants: including industry businesses, schools, teachers and students; (3) objectives: to cultivate students the ability to work after graduation. The difference between outcome-based curriculum design and the career-oriented curriculum design is shown in Table 1.

Table 1 Difference between OBE and the career-oriented curriculum design

\begin{tabular}{|c|c|c|}
\hline & Outcome-based curriculum design & The career-oriented curriculum design \\
\hline Keywords & Learning outcomes & Job post \\
\hline $\begin{array}{c}\text { Development } \\
\text { step }\end{array}$ & $\begin{array}{l}\text { Learning outcomes description } \\
\text { Analysis of Learning outcomes } \\
\text { Course development } \\
\text { Program course map }\end{array}$ & $\begin{array}{c}\text { Find job post } \\
\text { Job post description } \\
\text { Cultivation objectives of the major } \\
\text { Build courses system }\end{array}$ \\
\hline Course system & $\begin{array}{l}\text { From entry requirements to courses } \\
\text { learning, and achieving the program } \\
\text { outcomes finally }\end{array}$ & Platform courses system \\
\hline
\end{tabular}

After years of exploration and development of higher vocational education reform in China has been noticed, including career-oriented course system design, learning area curriculum development, working process-oriented curriculum design. These reforms have broken the traditional education mode, gradually from the teacher as the center to the students as the center of application ability training model. However, due to national conditions, teaching environment, traditional thinking and other constraints, the reforms still stay in the form. Borrowing from the more mature and modern vocational education reform model, is one way to promote the reform of vocational education in China.

Learning outcomes and course objectives are described observably and measurably in OBE course development model. However, the descriptions of training objectives and curriculum objectives are no testability and no universally accepted standard in China. OBE model pay attention to learning outcomes, and as the only standard of completing the program study. In China, the entry requirements and the teaching process are more important than learning outcomes. Therefore, while learning from foreign advanced vocational education curriculum model, the education model with Chinese characteristics should be explored.

\section{References}

[1] Guangmei Li. “Outcome- based educational theory and its applications.” Review of Education. (2007), p.51-54

[2] Jing Bo. "Outcome- based Education: Principles and Strategies.” Comparative Education Review. 2003, 159(8), p.40-43

[3] Information on http://www.nait.ca/39248.htm

[4] Guicheng Wang, Yuyan Xia, Jinchao Cai. "Results-oriented education model and Reference.” Forum on Contemporary Education. 2009(12), p.17-19

[5] Zhigang Song, Hong Chen, Genping Wang. "Outcome-Based Program Development: A Case Study of OBE Teaching Reform in Northern Alberta Institute of Technology.” Journal of Shenzhen Polytechnic, 12(1), (2013), p. 63-66

[6] ShenZhen Polytechnic. The collection of program teaching standard, Higher Education Press. (2008) 